\title{
Differentiated Thyroid Gland Carcinoma Under 55 Years AJCC v8 Stage
}

National Cancer Institute

\section{Source}

National Cancer Institute. Differentiated Thyroid Gland Carcinoma Under 55 Years A/CC v8 Stage. NCI Thesaurus. Code C140962.

A differentiated thyroid gland carcinoma stage for patients under 55 years of age defined according to the AJCC 8th edition criteria. 